PALABRAS CLAVE

Crisis financiera

Política fiscal

Macroeconomía

Tipos de cambio

Tasas de interés

Estabilización económica

Brasil

Manoel Carlos de Castro Pires

Técnico del Instituto de Investigación

Económica Aplicada (IPEA) y

Coordinador general de política fiscal de la Secretaría de Política Económica (SPE)/

Ministerio de Hacienda

œ manoel.pires@ipea.gov.br

Fábio Goto

Coordinador general de construcción de modelos de la Secretaría de Política Económica (SPE)/Ministerio de Hacienda

œfabio.goto@fazenda.gov.br

Bruno Rocha

Analista de finanzas y control de la Secretaría de Política Económica (SPE)/

Ministerio de Hacienda

œ bruno.r.silva@fazenda.gov.br
REVISTA CEPAL 102 DICIEMBRE 2010

\section{La política fiscal en tiempos de crisis; efectos macroeconómicos del superávit primario}

\author{
Manoel Carlos de Castro Pires, Fábio Goto y Bruno Rocha
}

L

a crisis financiera internacional que afectó a la economía brasileña en el tercer trimestre de 2008 exigió varias respuestas de política económica. Con respecto a la política fiscal, las medidas expansionistas adoptadas culminaron con la inviabilidad de la meta fiscal formalmente reducida en abril de 2009. El objetivo de este artículo es analizar los efectos macroeconómicos de la reducción de la meta de superávit primario y evaluar sus repercusiones en el nivel de actividad, la estructura temporal de la tasa de interés y el tipo de cambio. 


\section{I}

\section{Introducción}

La profundización de la crisis financiera internacional a partir del tercer trimestre de 2008 renovó el interés de la teoría macroeconómica en el papel anticíclico de la política fiscal. El interés en dicha función, que antes era muy clara y se basaba en la idea de que era necesario implementar políticas activas de administración de la demanda agregada (también llamadas keynesianas), perdió fuerza a mediados de los años setenta por dos razones principales. La primera, reconocida por Tobin (1982), es que los modelos de análisis keynesiano de la época eran estáticos y, en consecuencia, subestimaron las repercusiones de la política fiscal en la sostenibilidad de la deuda pública. La segunda razón es que los aumentos del déficit público deberían compensarse mediante superávits primarios en el futuro. En ese caso, los agentes económicos anticiparían el incremento de los impuestos en el futuro y, por consiguiente, la expansión fiscal no tendría efectos macroeconómicos, pues sería perfectamente compensada por el retroceso de la demanda agregada privada, argumento conocido como equivalencia ricardiana (Barro, 1979).

Durante muchos años, la preocupación por la sostenibilidad de la deuda y el propio cuestionamiento teórico sobre la eficacia de la política fiscal relegaron el uso de ese instrumento a un plano inferior con respecto a otros, entre ellos, la política monetaria. ${ }^{1}$

No obstante los intentos de revivir algunos aspectos de la política fiscal, como la idea de que los factores exógenos positivos pueden acrecentar el rendimiento del capital privado - entre ellos, las inversiones públicas en infraestructura y los gastos en educación-, es importante reconocer el cambio de enfoque de ese debate, que examina la política fiscal en un contexto mucho más estructural que como instrumento de política anticíclica.

Sin embargo, esas recomendaciones fueron desechadas por el pragmatismo que asumieron los encargados

$\square$ Las opiniones y resultados presentados en este artículo corresponden única y exclusivamente a sus autores y no representan necesariamente la visión de la institución a la que pertenecen.

${ }^{1}$ Blinder (2006) presenta la evolución de ese pensamiento y concluye que la política fiscal debería utilizarse solo cuando se agota la política monetaria, es decir, cuando se alcanza lo que en la literatura comúnmente se denomina el "límite inferior para la tasa de interés", que supone que la tasa de interés nominal llega a un valor próximo a cero. de la formulación de políticas en la economía mundial ante los acontecimientos provocados por la crisis financiera, que redundó en un modelo de política fiscal tan expansionista y poco convencional como la ayuda financiera a las empresas y la compra de activos "tóxicos" de los bancos.

Si bien las políticas para enfrentar las crisis aplicadas en el Brasil pueden considerarse convencionales en comparación con las implementadas en el resto del mundo, han sido objeto de varias críticas. El primer tipo de crítica se basa en la percepción general de que existe un límite de endeudamiento para la economía brasileña, el cual condiciona el potencial anticíclico de la política fiscal. ${ }^{2}$ En consecuencia, la reducción de la meta de superávit primario estaría limitada por otros objetivos y, en ese caso, la función de los responsables de formular políticas sería calibrar esa reducción para no comprometer la sostenibilidad, incluso a corto plazo, de la deuda pública. ${ }^{3}$ Dada esa preocupación, se puede constatar que el debate sobre los efectos de la reducción de la meta fiscal en el nivel de actividad todavía no se ha agotado.

El segundo tipo de crítica consiste en que el Brasil no estaba en la situación límite de establecer un piso inferior para la actuación de la política monetaria. De esa forma, la función anticíclica de la política fiscal impediría una reducción más pronunciada de la tasa de interés (Parnes y Goldfajn, 2008). Por otra parte, se sabe que los canales de transmisión de la política monetaria

\footnotetext{
${ }^{2}$ Como ejemplo, basta observar que cuando se divulgó la reducción de la meta de superávit primario del $3,8 \%$ del producto interno bruto (PIB) al 2,5\% del PIB en abril de 2009, se presentaron las proyecciones futuras para la deuda pública, pero no se estimaron las repercusiones del impulso fiscal en el PIB, que era el principal objetivo de la medida. ${ }^{3}$ Es importante tener en cuenta las propuestas existentes de medición de indicadores fiscales. Hemming y Ter-Minassian (2004) reconocen que el concepto de superávit primario puede causar sacrificios que repercuten en el crecimiento a largo plazo, entre ellos, el recorte de la inversión en infraestructura. Sin embargo, afirman que muchos países no están preparados técnicamente para adecuarse a una regla alternativa, como la regla de oro que procura equilibrar el presupuesto con la meta de resultado corriente y no de capital. Una posibilidad es la propuesta elaborada por Blanchard y Giavazzi (2004) de que las inversiones no deben considerarse en el concepto de superávit primario. En ese sentido, en el Brasil se ha adquirido experiencia relevante con ese procedimiento por medio del Programa de Parcelamiento Incentivado (PPI). Véase más información sobre el caso brasileño en Silva y Pires (2008).
} 
en el Brasil no son perfectos, de modo que incluso una marcada disminución de la tasa de interés puede no bastar para estimular la actividad económica con la velocidad deseada (Andrade y Pires, 2009). ${ }^{4}$

La tercera crítica es que la política fiscal anticíclica profundizaría el desequilibrio externo en la economía brasileña al estimular la demanda agregada. Esa política provocaría una devaluación cambiaria excesiva y un aumento de la inflación (Bacha, 2008). La medida en que este argumento resultaría verdadero dependería de la respuesta de las importaciones y las exportaciones en el mercado nacional e internacional,

${ }^{4}$ De todos modos, cabe destacar que las características institucionales del sistema financiero nacional hacen que el límite inferior para la tasa de interés sea diferente de cero. En realidad, el límite inferior para la tasa de interés en el Brasil es de alrededor del 8,5\% debido al rendimiento de las cajas de ahorro, que estipula un límite bastante sólido a la actuación de la política monetaria. del modo en que la deflación global afectaría a los índices locales de precios y de la combinación de la devaluación cambiaria con la reducción de los precios de los productos básicos.

El objetivo de este artículo es presentar los efectos macroeconómicos de la reducción de la meta de superávit primario en el Brasil en 2009, con énfasis en sus repercusiones a corto plazo. Además de esta introducción, el trabajo se divide en cuatro secciones. En la segunda sección se presentan las principales medidas de estímulo fiscal adoptadas por el Gobierno Federal hasta el primer semestre de 2009, que contribuyeron a la reducción de la meta de superávit primario en el año, mientras que en la tercera se describen la metodología de trabajo y la base de datos. En la cuarta sección se estiman los efectos del superávit primario en la actividad económica, la estructura temporal de la tasa de interés y el tipo de cambio, y en la última se detallan las principales conclusiones del trabajo.

\section{II}

\section{Principales medidas de estímulo fiscal}

La velocidad con que la crisis se instauró en el Brasil a partir de fines del tercer trimestre de 2008 provocó reacciones distintas respecto de los diversos instrumentos de política económica. Si bien al inicio no estaba claro el comportamiento futuro de la tasa de inflación, que condicionaba las decisiones de política monetaria, la política fiscal permitió que se tomaran las primeras medidas de estímulo a la demanda agregada. ${ }^{5}$

En diciembre de 2008, el Ministerio de Hacienda anunció tres medidas de desgravación fiscal, a saber:

i) Reducción de la parte alícuota del impuesto sobre la renta de las personas físicas (IRPF) en 2009 (estimada en 4.900 millones de reales), cuyo objetivo era estimular la demanda agregada.

\footnotetext{
${ }^{5}$ Los primeros efectos de la crisis se tradujeron en problemas de liquidez en el sistema interbancario y en operaciones cambiarias a través de derivados financieros colocados por diversas empresas. $\mathrm{Si}$ bien la discusión acerca de la tasa de interés estaba contaminada por los riesgos inflacionarios, es importante notar que el Banco Central del Brasil recurrió a políticas no convencionales, como el uso de reservas internacionales para financiar empresas con dificultades y reducción de los depósitos obligatorios para aliviar los problemas de liquidez en el sistema interbancario.
}

ii) Reducción hasta el mes de marzo de la parte alícuota del impuesto sobre los productos industrializados (IPI) respecto de los automóviles (estimada en 1.000 millones de reales), con el propósito de disminuir las existencias de ese sector que crecieron rápidamente en virtud de la gran contracción de la demanda.

iii) Desgravación del impuesto a las operaciones financieras (IOF) sobre el crédito al consumidor (estimada en 2.500 millones de reales), con miras al restablecimiento del crédito privado.

A fines de marzo de 2009, el Ministerio de Hacienda anunció el mantenimiento de la desgravación del IPI sobre los automóviles y amplió la medida a las motocicletas, incluida también en ese caso la Contribución para el Financiamiento de la Seguridad Social (COFINS). A fin de compensar la pérdida de recaudación con esa medida, se incrementó el IPI sobre el tabaco. La pérdida de ingresos netos derivada de esa medida se estimó en 700 millones de reales.

En abril se anunciaron otras dos medidas de desgravación fiscal: la reducción del IPI para los electrodomésticos de la línea blanca (estimada en 170 millones de reales) y la rebaja del IPI para algunos ítems de la construcción civil (estimada en 90 
millones de reales), ambas con el objetivo de reactivar la demanda agregada. En junio, el Gobierno Federal prorrogó todas las desgravaciones y desgravó varios bienes de capital. La pérdida de recaudación total con esas desgravaciones se estimó en 12.500 millones de reales (véase el cuadro 1 ).

Desde el punto de vista de las medidas de expansión de los gastos, cuando quedó clara la profundidad de la crisis el Gobierno Federal recurrió al aumento de las inversiones como medida anticíclica. Para ello se adoptaron las siguientes iniciativas: el retiro de las empresas del Grupo Petrobras del cálculo del superávit

CUADRO 1

\section{Estímulo fiscal mediante desgravaciones fiscales \\ (En miles de millones de reales)}

\begin{tabular}{|c|c|}
\hline Medidas fiscales & Estímulo en 2009 \\
\hline \multicolumn{2}{|l|}{ Desgravaciones de diciembre de 2008} \\
\hline $\begin{array}{l}\text { Impuesto sobre la renta de las personas físicas } \\
\text { (IRPF) }\end{array}$ & 4,90 \\
\hline $\begin{array}{l}\text { Impuesto sobre los productos industrializados } \\
\text { (IPI) - automóviles }\end{array}$ & 1,00 \\
\hline $\begin{array}{l}\text { Impuesto a las operaciones financieras (IOF) - } \\
\text { crédito al consumidor }\end{array}$ & 2,50 \\
\hline Total & 8,40 \\
\hline \multicolumn{2}{|l|}{ Desgravaciones de marzo de 2009} \\
\hline Prórroga del IPI - automóviles & 1,00 \\
\hline $\begin{array}{l}\text { Contribución para el Financiamiento de la Segu- } \\
\text { ridad Social (COFINS) de las motocicletas }\end{array}$ & 0,15 \\
\hline IPI - construcción civil & 0,35 \\
\hline Recomposición de los ingresos con IPI - tabaco & $-0,80$ \\
\hline Total & 0,70 \\
\hline \multicolumn{2}{|l|}{ Desgravaciones de abril de 2009} \\
\hline IPI - construcción civil & 0,09 \\
\hline IPI - línea blanca & 0,17 \\
\hline Total & 0,26 \\
\hline \multicolumn{2}{|l|}{ Desgravaciones de junio de 2009} \\
\hline IPI - bienes de capital & 0,41 \\
\hline Prórroga del IPI - automóviles & 1,79 \\
\hline Prórroga del IPI - línea blanca & 0,20 \\
\hline Prórroga de la COFIns de las motocicletas & 0,05 \\
\hline Prórroga del IPI - construcción civil & 0,69 \\
\hline Total & 3,15 \\
\hline
\end{tabular}

Fuente: elaboración propia. primario, con el objetivo de reducir sus restricciones a la inversión (estimadas en 15.000 millones de reales en 2009); el incremento del salario mínimo para estimular la demanda agregada (estimado en 8.700 millones de reales), y el paquete de vivienda (estimado en 6.000 millones de reales), que apuntaba a incentivar al sector de la construcción civil. Además, se amplió la red de protección social aumentando el acceso al seguro de desempleo y al Programa Bolsa Familia. El total de esas medidas se estima en 30.930 millones de reales (véase el cuadro 2). ${ }^{6}$

Como consecuencia de esa serie de medidas, el Gobierno Federal anunció en abril la reducción de la meta de superávit primario para el año 2009 del 3,8\% del PIB al 2,5\% del PIB, pudiendo utilizar además el espacio fiscal permitido por el PPI. De la reducción de la meta conviene señalar la exclusión de Petrobras del cálculo, estimado en el 0,5\% del PIB. La parte del Gobierno Federal se contrajo del 2,15\% del PIB al 1,4\% del PIB y la de estados y municipios se redujo del 0,95\% del PIB al $0,90 \%$ del PIB.

CUADRO 2

Estímulo fiscal mediante aumento de los gastos (En miles de millones de reales)

Medidas fiscales

Estímulo en 2009

Aumento de los gastos

Inversiones de Petrobras $^{\mathrm{a}} \quad 15,00$

$\begin{array}{lr}\text { Salario mínimo } & 8,70\end{array}$

Paquete de vivienda $\quad 6,00$

Seguro de desempleo $\quad 0,23$

$\begin{array}{ll}\text { Programa Bolsa Familia } & 1,00\end{array}$

Fuente: elaboración propia.

a Petróleo brasileño.

\footnotetext{
${ }^{6}$ Es relevante destacar que el mejoramiento del salario mínimo fue una medida anterior a la crisis. Sin embargo, se optó por incluirla en el análisis debido a su marcado efecto expansionista. Lo mismo podría decirse del incremento salarial de los funcionarios públicos. No obstante, este no fue incluido porque tendría efectos expansionistas solo a partir del segundo semestre de 2009, cuando los resultados ya indicaban una recuperación de la economía.
} 


\section{III}

\section{Metodología y descripción de la base de datos}

La estrategia de construcción de modelos adoptada en este trabajo puede atribuirse a lo que Hoover, Johansen y Juselius (2008) definen como enfoque probabilista (Haavelmo, 1944). Sin embargo, es importante señalar que, a diferencia de lo que puede pensarse, el enfoque probabilista no significa el límite extremo de la investigación sin teoría. La idea básica es que los datos pueden utilizarse muchas veces para orientar la teoría.

La estructura elegida comprende un modelo bastante estilizado, llamado núcleo, y modelos auxiliares que lo complementan. Como señalan Bardsen y otros (2005), la construcción de modelos macroeconométricos en ese formato presenta las ventajas de incorporar elementos que todavía no fueron suficientemente analizados por la teoría y de poseer flexibilidad suficiente para atender las demandas de los usuarios de modelos, sobre todo de los encargados de formular políticas. En ese sentido, esta metodología supone la característica de modelos que dominan a otros modelos (encompassing), defendida por Clements y Hendry (2008). ${ }^{7}$

Una preocupación importante con respecto a la construcción de modelos, sobre todo en el caso de los datos brasileños, se refiere a la existencia de rupturas estructurales. En efecto, es importante destacar que los parámetros obtenidos deben ser constantes e invariables ante ciertas formas de intervención, entre ellas, las manipulaciones en las variables exógenas (Bardsen y otros, 2005). De ese modo, la búsqueda de parámetros robustos se realizó a partir de formas alternativas de estimación, de cambios en el tamaño de la muestra y mediante el uso de métodos de parámetros variables.

Al aplicar esa metodología el análisis se dividió en tres partes. En la primera (estimación del núcleo) se evalúa el efecto del superávit primario en el nivel de actividad mediante un modelo equivalente al utilizado por los bancos centrales y compuesto por tres ecuaciones: una curva Is, una curva de Phillips y una regla de política monetaria. Mientras el superávit primario se

\footnotetext{
${ }^{7}$ De acuerdo con Clements y Hendry (2008), un buen modelo debe por lo menos absorber o englobar (encompassing) los modelos ya existentes, pues esa característica garantiza que el programa de investigación sea positivo.
}

modela directamente en la curva is (de conformidad con Lambertini y Rovelli (2003)), la estimación conjunta de esas ecuaciones es importante para controlar la endogénesis de la política económica, que podría sesgar los resultados.

La curva is se describe de la siguiente manera:

$$
y_{t}=c_{y}+\alpha_{1} y_{t-1}+\alpha_{2}\left(i_{t-1}-\pi_{t}\right)+\alpha_{3} s_{t}+e_{y, t}
$$

donde $c_{y}$ es el intercepto y $e_{t}$ es un término de error con media cero y varianza constante. La curva IS, tal como se propone en (1), muestra la forma en que el superávit primario $\left(s_{t}\right)$ y la tasa de interés real $\left(i_{t-1}-\pi_{t}\right)$ afectan al nivel de actividad económica $\left(y_{t}\right)$.

La curva de Phillips se define de la siguiente manera:

$$
\pi_{t}=\phi_{1} \pi_{t-1}+\left(1-\phi_{1}\right) E_{t} \pi_{t+1}+\phi_{2} y_{t}+e_{\pi, t}
$$

donde $\pi_{t}$ es la tasa de inflación, $e_{\pi, t}$ es un término de error con media cero y varianza constante.

El comportamiento de la política monetaria se define a partir de la regla:

$$
i_{t}=\lambda_{1} i_{t-1}+\lambda_{2}\left(E_{t} \pi_{t+1}-\bar{\pi}\right)+\lambda_{3} y_{t}+e_{i, t}
$$

que indica que la tasa de interés nominal reacciona según la desviación de la inflación $\left(\pi_{t}\right)$ con respecto a la meta $(\bar{\pi})$ y la brecha del producto, permitiendo además un componente de mitigación de la tasa de interés.

Una precisión relevante con respecto al modelo propuesto es que este tiene el objetivo de evaluar el efecto de la política fiscal en el corto plazo, pues solo de ese modo el superávit primario puede tratarse como una variable exógena. En evaluaciones de mediano plazo, el superávit primario debe respetar la restricción presupuestaria del gobierno, conforme con lo demostrado en la literatura sobre la sostenibilidad de la deuda pública (Bohn, 1997).

La base de datos para la estimación del núcleo del modelo está compuesta por la brecha del producto calculado por una tendencia lineal y cuadrática; la tasa de interés nominal a corto plazo es la tasa Sistema Especial de Liquidación y Custodia (SELIC); el superávit 
primario se refiere al del sector público consolidado como porcentaje del PIB, y la tasa de inflación se mide por el índice nacional de precios al consumidor en su concepto amplio (IPCA) acumulado en 12 meses. En el gráfico 1 se presenta la evolución de esas variables en el período que va del tercer trimestre de 1999 al cuarto trimestre de 2008.

Como se puede observar en el gráfico 1, la evolución de la brecha del producto presenta una reversión a la media que caracteriza a la serie como estacionaria. Conviene destacar que esto no ocurre en el período posterior a 2005. En el caso del superávit primario como proporción del PIB, la serie presenta una tendencia de crecimiento en el período de referencia, con algunas sacudidas adicionales en 2003 y 2005. En vista de esa tendencia creciente, se puede decir que la serie presenta reversión a la media en torno de la tendencia, de modo que esa variable también sería estacionaria. En el caso de la tasa de interés SELIC, es más difícil caracterizarla como una serie estacionaria, pues la reversión a la media no aparece con claridad. Sin embargo, cabe notar que esta sufrió una fuerte conmoción en el segundo semestre de 2002 y que al tener en cuenta esa observación aberrante, la reversión a la media se vuelve más evidente. La tasa de inflación constituye un caso análogo: al considerar aberrantes las observaciones del segundo semestre de 2002 se puede concluir que la serie también es estacionaria.

Para probar esas impresiones sobre las características de las variables se utilizaron la prueba de raíz unitaria de Ng y Perron (2001) y la prueba de Saikkonen y Lutkepohl (2002), que permiten la existencia de rupturas estructurales en el conjunto de datos. Si bien en la prueba de Ng y Perron no se rechaza la hipótesis nula de raíz unitaria en el caso del superávit primario, en la prueba de Saikkonen y Lutkepohl se aprecia que esta serie de superávit primario puede considerarse estacionaria cuando la serie está controlada por la ruptura estructural
GRÁFICO 1

\section{Evolución de las variables}

Brecha del producto

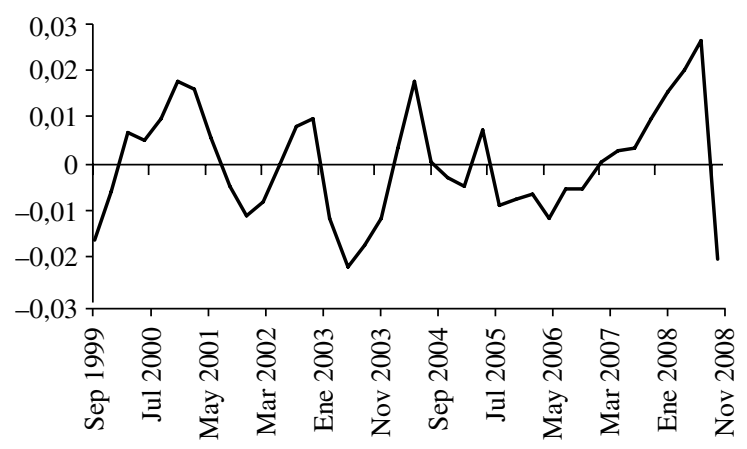

Tasa del Sistema Especial de Liquidación y Custodia

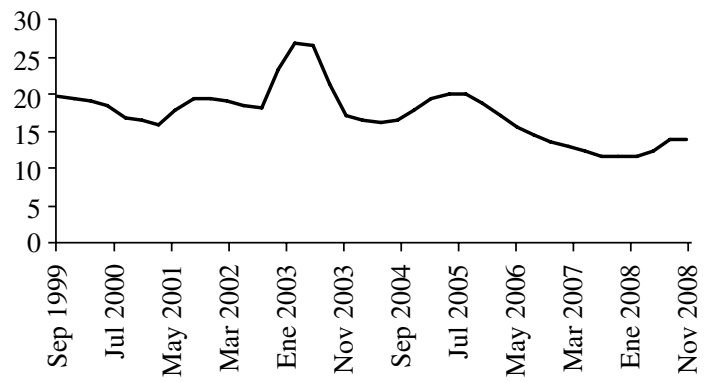

Superávit primario como proporción del PIB

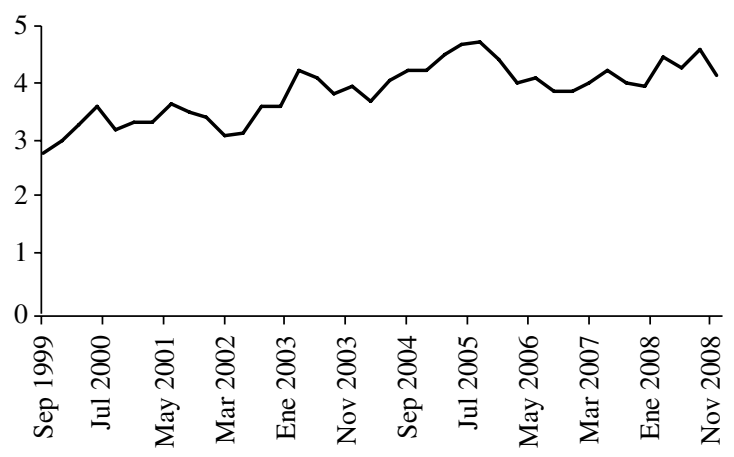

Índice nacional de precios al consumidor en concepto amplio

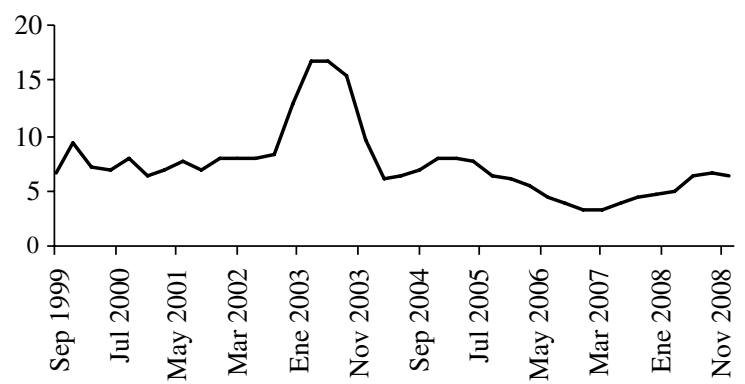

Fuente: elaboración propia.

PIB: producto interno bruto. 
(modelada como una variable ficticia de impulso) en 2003. En el caso de las demás variables, las dos pruebas arrojaron las mismas conclusiones.

La segunda parte del análisis se concentra en la evaluación de los modelos auxiliares. Por medio del primer modelo auxiliar se estima el efecto del superávit primario en la estructura temporal de la tasa de interés. Para incorporar las repercusiones de la política fiscal en la estructura temporal de las tasas de interés, es importante asumir una hipótesis teórica sobre el comportamiento de la estructura temporal. En ese sentido, se adopta la tradicional hipótesis de las expectativas. Sin embargo, cabe señalar que con frecuencia en los datos brasileños se rechaza la hipótesis de las expectativas. ${ }^{8}$ Para adecuar el modelo a las pruebas empíricas existentes se adopta una especificación de la teoría de las expectativas, que asume que la prima de riesgo puede variar en el tiempo (conforme con Guillén y Tabak (2007)). De ese modo, la estructura temporal puede modelarse por medio de un modelo espacio-estado de la siguiente forma: ${ }^{9}$

$$
R_{t}^{\text {swap }, d}=i_{t}+r_{t}^{d}+v_{t}
$$

$\left(i_{t}=\right.$ tasa SELIC $)$

$$
r_{t}^{d}=r_{t-1}^{d}+\mu_{t}
$$

donde $R_{t}^{\text {swap }}$ es la tasa de interés swap de 30, 60, 90, 120,180 y 360 días $(d)$. El exceso de rendimiento (dado por $R_{t}^{\text {swap }}-i_{t}$ se define como una prima de riesgo $\left(r_{t}\right)$ modelada como variable en el tiempo agregado de una variable aleatoria $v_{t} \sim\left(0, \omega^{2}\right)$. Para estimar la prima de riesgo variable en el tiempo mediante el filtro de Kalman, es necesario imponer una estructura estocástica. Nuestra hipótesis es que esta sigue un camino aleatorio (random walk) donde $\mu_{t} \sim\left(0, \sigma^{2}\right)$ de conformidad con la ecuación (5).

A continuación se procura establecer la manera en que las variables macroeconómicas (inflación, brecha del producto y superávit primario) afectan a la prima de riesgo por medio del sistema de ecuaciones: ${ }^{10}$

\footnotetext{
${ }^{8}$ Véanse más detalles sobre el rechazo de la teoría de las expectativas en el Brasil bajo la hipótesis de que la prima de riesgo es constante en el tiempo, en Tabak y Andrade (2003) y Lima e Issler (2003).

${ }^{9}$ Véase un análisis de los modelos espacio-estado en Commandeur y Koopman (2007).

${ }^{10} \mathrm{Al}$ admitir que la prima de riesgo es un camino aleatorio en la ecuación (5) y, a continuación, al modelar la prima de riesgo como un modelo de desfases distribuidos (ADL) en (6), se asume que el carácter no estacionario originado en (5) ocurre por un posible problema de mala especificación. En la literatura sobre series temporales se des-
}

$$
r_{t}^{d}=\rho^{d} r_{t-1}^{d}+\beta_{0}^{d}+\beta_{\pi}^{d} \pi_{t}+\beta_{s}^{d} s_{t}+\beta_{y}^{d} y_{t}+\varepsilon_{t}^{d}
$$

En el gráfico 2 se presenta la evolución de la prima de riesgo estimada mediante el filtro de Kalman en sus diversos vencimientos. Se puede observar que la prima de riesgo presenta una elevada volatilidad en el período 1999-2003 y posteriormente se estabiliza. El segundo aspecto interesante es que las tasas más largas poseen una mayor amplitud que las más cortas.

Con el segundo modelo auxiliar se evalúan las repercusiones del superávit primario en el tipo de cambio. En efecto, el modelo más tradicional sobre el tipo de cambio es la paridad del poder adquisitivo (PPA). La investigación respecto de la validez de la PPA normalmente consiste en probar si el tipo de cambio real puede modelarse como una variable estacionaria (Rogoff, 1996). En ese sentido, el análisis sigue de cerca los resultados de Juselius (2007), que prueba la PPA en Alemania. Dichos resultados muestran que la PPA solo se respeta cuando se incorpora en el análisis el efecto del diferencial de interés a corto y largo plazo. La principal reflexión del estudio es que las desviaciones sistemáticas de la PPA serían posibles a partir de la incorporación en el análisis de los efectos de los movimientos de capitales en el tipo de cambio. En este sentido, el candidato natural para las desviaciones del tipo de cambio de la PPA sería el diferencial de interés.

Como corolario de esa literatura se propone un modelo para el tipo de cambio similar al presentado para la estructura temporal de la tasa de interés. Los movimientos del tipo de cambio se definen sobre la base de la fluctuación del nivel de precios nacional en relación con el nivel de precios internacional. Las desviaciones resultantes se modelan como función de la prima de riesgo, tal como la que se obtuvo en (5). ${ }^{11}$ Además de utilizarse la prima de riesgo para modelar el tipo de cambio real, conviene señalar que el nivel de equilibrio del tipo de cambio no puede ser considerado constante, pues existe una serie de factores que pueden

taca que el carácter no estacionario puede surgir a consecuencia de la falta de linealidades, rupturas estructurales u omisión de variables relevantes en el proceso generador de datos. Esta hipótesis puede ser rechazada en el caso en que la estimación del parámetro $\rho$ sea menor que 1 , como también sucede con las estimaciones obtenidas.

${ }^{11}$ Con respecto a los resultados obtenidos por Juselius (2007), conviene subrayar que se optó por utilizar la prima de riesgo y no el diferencial de interés en virtud de la posible multicolinealidad, pues las dos variables son funciones de la tasa de interés a corto plazo. Además, se debe destacar que mientras en el caso de Alemania es razonable suponer una prima de riesgo próxima a cero, no ocurre lo mismo en el caso del Brasil, siendo este un factor relevante para componer el diferencial de rendimiento entre activos externos e internos. 


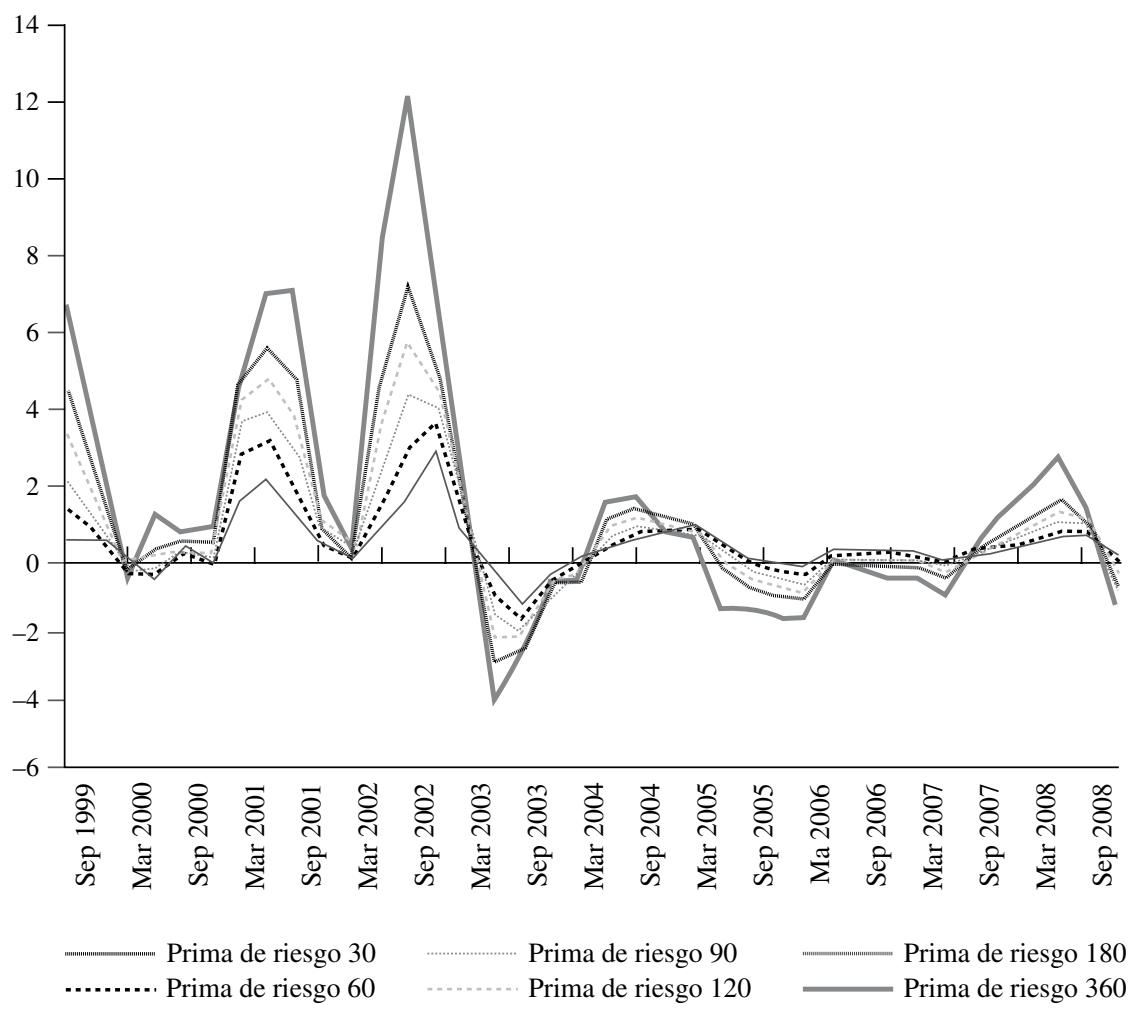

Fuente: elaboración propia.

afectar su valor, entre ellos, los choques nominales y diferenciales de productividad. ${ }^{12}$

En el gráfico 3 se presenta la evolución del tipo de cambio real en logaritmo natural en el período que va del tercer trimestre de 1999 al cuarto trimestre de 2008. La primera característica relevante de la serie consiste en la dificultad para observar reversión a la media. La segunda característica principal es que existen algunas importantes sacudidas positivas en 2001 y 2002. Con la prueba de Ng y Perron se confirma la ausencia de reversión a la media, pues no se rechaza la hipótesis nula de raíz unitaria. Al modelar el tipo de cambio real con una ruptura estructural, en la prueba de Saikonen y Lutkepohl se confirman los resultados obtenidos anteriormente.

En consecuencia, al haber rechazado la PPA, en el modelo propuesto se incorpora el efecto de la prima de riesgo en el tipo de cambio real, además de modelar la media como variable en el tiempo por medio del filtro de Kalman de la siguiente forma:

\footnotetext{
12 Véanse Dornbusch (1976), Balassa (1964) y Samuelson (1964).
}

$$
\begin{gathered}
q_{t}=\psi_{t}+\omega r_{t}^{d}+\varepsilon_{q, t} \\
\psi_{t}=\psi_{t-1}+\varepsilon_{\psi, t}
\end{gathered}
$$

donde $q$ es el tipo de cambio real, $\psi_{t}$ es la media variable en el tiempo que sigue la estructura de un camino aleatorio y $\varepsilon_{\psi, t}$ y $\varepsilon_{q, t}$ son términos de error con media cero y varianza constante.

En resumen, el modelo está compuesto por un núcleo y dos modelos auxiliares. El mecanismo de transmisión que ha de evaluarse indica, por lo tanto, la manera en que el superávit primario afecta, en el corto plazo, al nivel de actividad, la estructura temporal y el tipo de cambio. En el gráfico 4 se ilustra el mecanismo de transmisión macroeconómica del superávit primario. Además de los efectos indicados se deben considerar los efectos indirectos, entre ellos el nivel de inflación, la tasa de interés a corto plazo y la estructura temporal por medio de la actividad económica (trazado). 
GRÁFICO 3

\section{Evolución del logaritmo del tipo de cambio real}

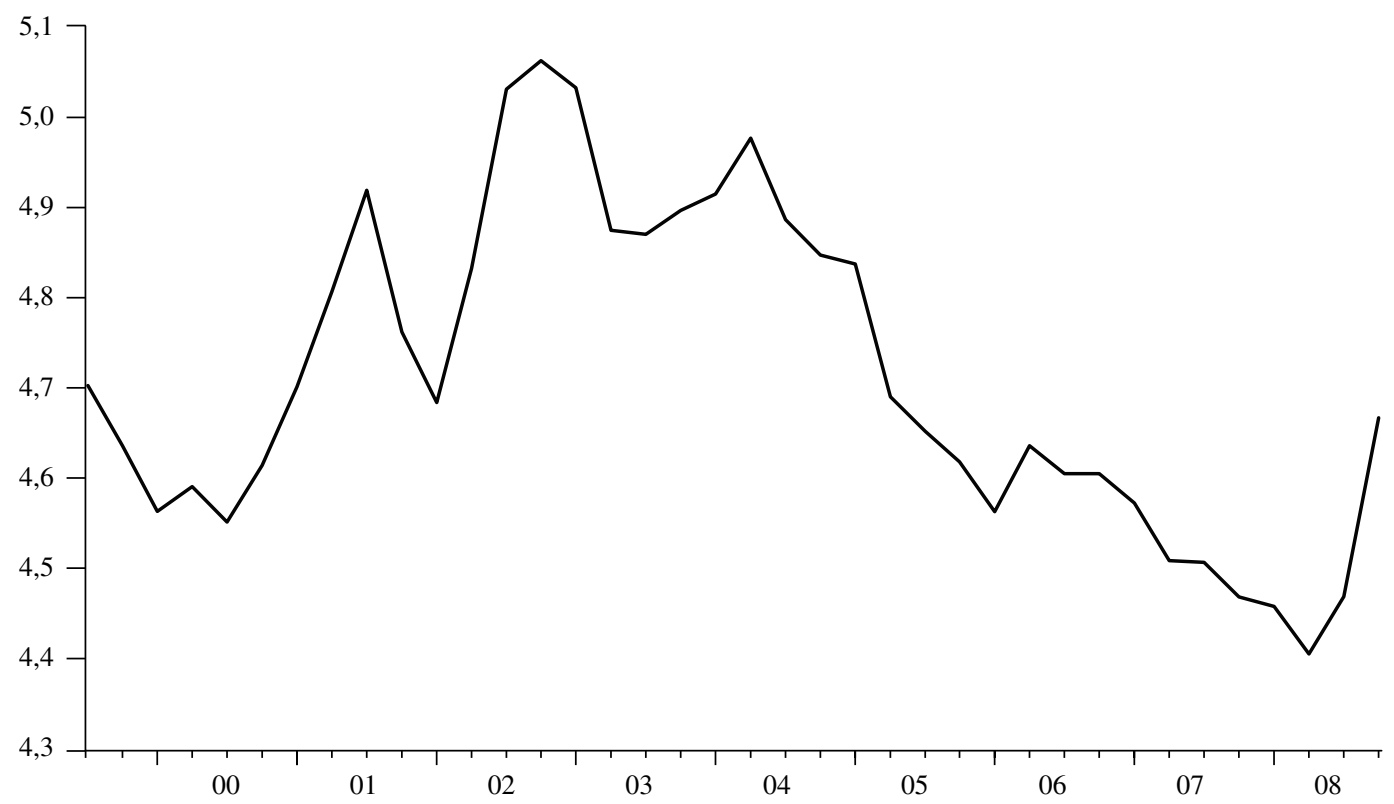

Fuente: elaboración propia.

GRÁFICO 4 Mecanismo de transmisión del superávit primario

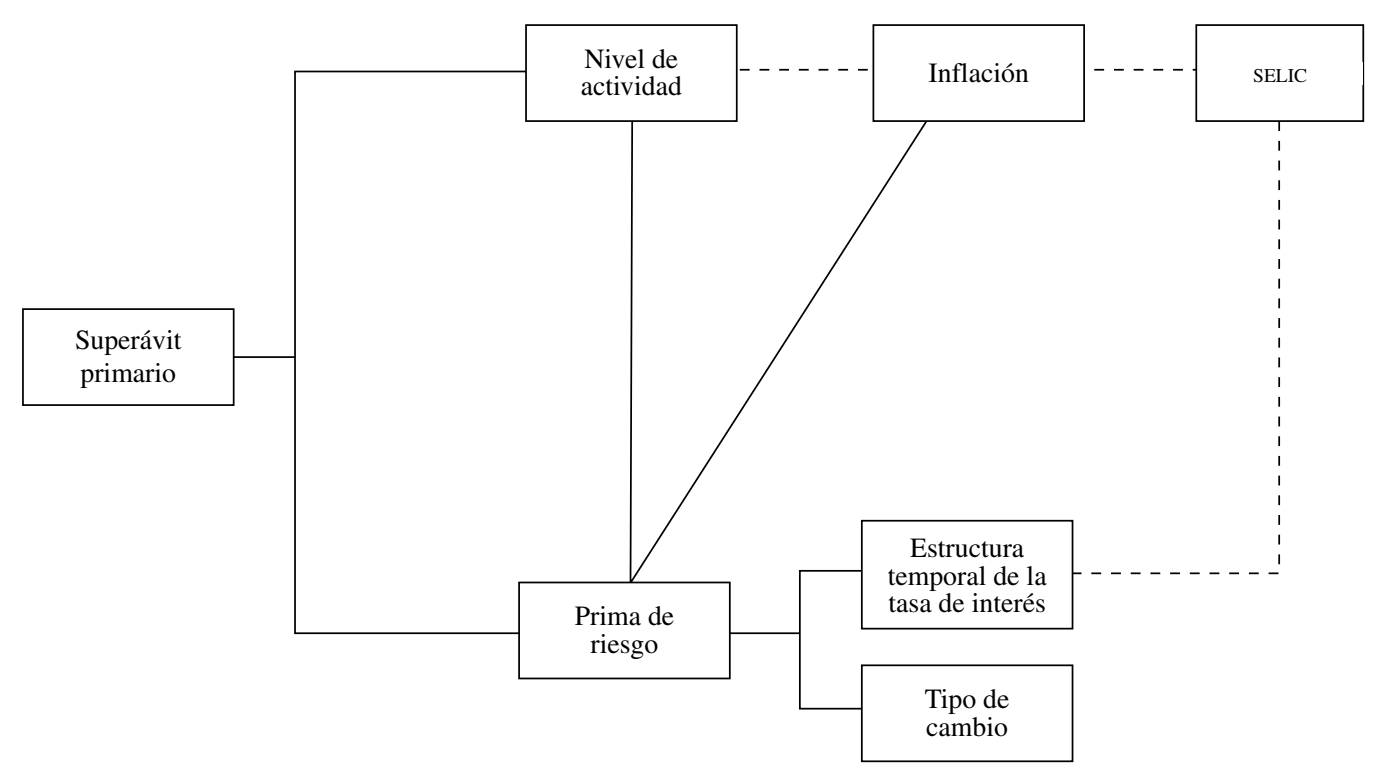

Fuente: elaboración propia.

SELIC: Sistema Especial de Liquidación y Custodia. 


\section{IV}

\section{Estimaciones}

La estimación del núcleo del modelo se realizó mediante mínimos cuadrados ordinarios (MCO), regresión aparentemente no relacionada y método generalizado de momentos (MGM) (véase el cuadro 3). En el caso del MGM, en la lista de instrumentos se consideraron los desfases de 1 a 3 de las propias variables del modelo. Los parámetros son muy similares en los tres métodos de estimación. Por ejemplo, se estima que el efecto del superávit primario en el nivel de actividad está entre $\neq 0,377$ y $-0,430$, mientras que solo en la estimación por MGM ese efecto puede considerarse significativo. Con respecto a la significación estadística, lo mismo vale para la política monetaria cuyos efectos se estiman entre $-0,131$ y $-0,142$.

La curva de Phillips indica un elevado grado de inercia inflacionaria. El coeficiente estimado se sitúa entre 0,779 y 0,835 , cifras que suponen una inflación excesivamente regresiva. El coeficiente de la brecha del producto es significativo en las tres estimaciones (entre $0,373$ y 0,424$)$.

El gradualismo de la política monetaria (conforme con el parámetro $\lambda_{l}$ ) es bastante elevado. En realidad, ese parámetro se aproxima a la raíz unitaria, lo que puede causar dudas sobre el carácter estacionario del proceso y, por ende, respecto de la validez de la inferencia. Si bien las pruebas de raíz unitaria se aplicaron para permitir el análisis, es verdad que suelen presentar problemas de bajo poder de prueba. Por otra parte, en los resultados obtenidos por Rothenberg y Stock (1997) se señala que la inferencia convencional próxima de la raíz unitaria puede considerarse válida, de modo que los resultados que se obtuvieron constituyen una buena aproximación.

El efecto estimado del superávit primario en la estructura temporal sugiere que este eleva la tasa de interés en los diversos vencimientos (véase el cuadro 4). En ambos períodos de estimación es común observar que las estimaciones mediante mínimos cuadrados ordinarios y regresión aparentemente no relacionada presentan efectos significativos, y que en las estimaciones con el método generalizado de momentos los resultados no son estadísticamente significativos en los intervalos más cortos de la estructura temporal (30 y 60 días). A su vez, en las pruebas obtenidas se indica que los efectos varían

CUADRO 3

Estimaciones del modelo de pequeña escala

\begin{tabular}{|c|c|c|c|c|c|c|}
\hline \multirow{2}{*}{ Variables } & \multicolumn{2}{|c|}{$\begin{array}{l}\text { Mínimos cuadrados } \\
\text { ordinarios }\end{array}$} & \multicolumn{2}{|c|}{$\begin{array}{l}\text { Regresión aparentemente no } \\
\text { relacionada }\end{array}$} & \multicolumn{2}{|c|}{$\begin{array}{l}\text { Método generalizado } \\
\text { de momentos }\end{array}$} \\
\hline & Coeficiente & Estadística t & Coeficiente & Estadística t & Coeficiente & Estadística t \\
\hline$c_{y}$ & 0,026 & 1,42 & 0,027 & 1,60 & 0,028 & 4,01 \\
\hline $\begin{array}{l}y \\
\alpha\end{array}$ & 0,471 & 2,97 & 0,482 & 3,22 & 0,493 & 10,69 \\
\hline$\alpha_{2}$ & $-0,137$ & $-1,51$ & $-0,131$ & $-1,55$ & $-0,142$ & $-3,269$ \\
\hline$\alpha_{3}^{2}$ & $-0,377$ & 1,02 & $-0,430$ & $-1,25$ & $-0,400$ & $-2,778$ \\
\hline$R^{2}$ & 0,3107 & & 0,3100 & & 0,3096 & \\
\hline$\phi_{1}$ & 0,779 & 9,75 & 0,801 & 10,88 & 0,835 & 29,60 \\
\hline$\phi_{2}$ & 0,373 & 1,76 & 0,397 & 1,95 & 0,424 & 10,28 \\
\hline$R^{2}$ & 0,8221 & & 0,8217 & & 0,8196 & \\
\hline$\lambda_{l}$ & 0,965 & 79,42 & 0,965 & 87,31 & 0,966 & 205,7 \\
\hline$\lambda_{2}^{T}$ & 0,757 & 4,32 & 0,638 & 4,19 & 0,826 & 11,90 \\
\hline$\lambda_{3}^{2}$ & 0,439 & 2,72 & 0,477 & 3,13 & 0,405 & 10,06 \\
\hline$R^{2}$ & 0,9052 & & 0,9033 & & 0,9049 & \\
\hline
\end{tabular}

Fuente: elaboración propia.

Nota: Número total: 110 observaciones. En el caso del método generalizado de momentos, la estadística J no rechazó la hipótesis nula de validez de los instrumentos probados. Los instrumentos utilizados fueron los desfases 1, 2 y 3 de la brecha del producto y del superávit primario, los desfases 1 y 2 del índice nacional de precios al consumidor en su concepto amplio (IPCA) y los desfases 2 y 3 de la tasa de interés.

$R^{2}: \quad$ Bondad de ajuste. 
CUADRO 4

Determinantes macroeconómicos de la prima de riesgo

\begin{tabular}{|c|c|c|c|c|c|c|}
\hline \multirow{2}{*}{ Variables } & \multicolumn{2}{|c|}{ Mínimos cuadrados ordinarios } & \multicolumn{2}{|c|}{$\begin{array}{l}\text { Regresión aparentemente } \\
\text { no relacionada }\end{array}$} & \multicolumn{2}{|c|}{$\begin{array}{l}\text { Método generalizado } \\
\text { de momentos }\end{array}$} \\
\hline & Coeficiente & Estadística t & Coeficiente & Estadística t & Coeficiente & Estadística t \\
\hline$\beta_{0}{ }^{30}$ & 0,0097 & 2,82 & 0,0093 & 2,92 & 0,0062 & 1,63 \\
\hline$\rho^{30}$ & 0,8623 & 9,83 & 0,6860 & 14,09 & 0,8499 & 9,77 \\
\hline$\beta_{\pi}^{30}$ & $-0,0300$ & $-2,11$ & $-0,0180$ & $-1,44$ & $-0,0191$ & $-1,87$ \\
\hline$\beta_{s}^{30}$ & 0,1955 & 2,36 & 0,2060 & 2,68 & 0,1257 & 1,27 \\
\hline$\beta_{y}{ }^{30}$ & 0,1260 & 3,49 & 0,1332 & 3,98 & 0,1979 & 3,73 \\
\hline$R^{2}$ & 0,80 & & 0,78 & & 0,77 & \\
\hline$\beta_{0}{ }^{60}$ & 0,0142 & 2,84 & 0,0151 & 3,28 & 0,0104 & 1,79 \\
\hline$\rho^{60}$ & 0,8332 & 9,81 & 0,6726 & 15,26 & 0,8273 & 10,39 \\
\hline$\beta_{\pi}^{60}$ & $-0,0410$ & $-1,96$ & $-0,0236$ & $-1,31$ & $-0,0278$ & $-1,89$ \\
\hline$\beta_{s}^{60}$ & 0,2898 & 2,36 & 0,3396 & 3,03 & 0,2130 & 1,45 \\
\hline$\beta_{v}^{60}$ & 0,1923 & 3,65 & 0,2084 & 4,29 & 0,2797 & 3,91 \\
\hline$R^{2}$ & 0,82 & & 0,80 & & 0,81 & \\
\hline$\beta_{0}^{90}$ & 0,0196 & 2,98 & 0,0217 & 3,58 & 0,0165 & 2,13 \\
\hline$\rho^{90}$ & 0,8180 & 9,76 & 0,6771 & 16,08 & 0,8205 & 10,62 \\
\hline$\beta_{\pi}^{90}$ & $-0,0542$ & $-1,99$ & $-0,0340$ & $-1,44$ & $-0,0439$ & $-2,09$ \\
\hline$\beta_{s}^{90}$ & 0,4038 & 2,48 & 0,4833 & 3,28 & 0,3376 & 1,77 \\
\hline$\beta_{v}^{90}$ & 0,2379 & 3,43 & 0,2614 & 4,12 & 0,3154 & 3,64 \\
\hline$R^{2}$ & 0,83 & & 0,82 & & 0,83 & \\
\hline$\beta_{0}{ }^{120}$ & 0,0258 & 3,03 & 0,0286 & 3,72 & 0,0242 & 2,40 \\
\hline$\rho^{I 20}$ & 0,7979 & 9,43 & 0,6990 & 16,90 & 0,8171 & 10,49 \\
\hline$\beta_{\pi}{ }^{120}$ & $-0,0697$ & $-2,02$ & $-0,0519$ & $-1,75$ & $-0,0681$ & $-2,30$ \\
\hline$\beta_{s}{ }^{120}$ & 0,5307 & 2,50 & 0,6237 & 3,33 & 0,4907 & 2,06 \\
\hline$\beta_{y}{ }^{120}$ & 0,2689 & 3,05 & 0,2935 & 3,66 & 0,3123 & 3,00 \\
\hline$R^{2}$ & 0,84 & & 0,83 & & 0,85 & \\
\hline$\beta_{0}{ }^{180}$ & 0,0332 & 3,09 & 0,0360 & 3,75 & 0,0333 & 2,59 \\
\hline$\rho^{I 80}$ & 0,7838 & 9,07 & 0,7154 & 16,93 & 0,8155 & 10,12 \\
\hline$\beta_{\pi}^{180}$ & $-0,0878$ & $-2,05$ & $-0,0727$ & $-1,97$ & $-0,0964$ & $-2,35$ \\
\hline$\beta_{s}^{180}$ & 0,6850 & 2,54 & 0,7745 & 3,30 & 0,6686 & 2,28 \\
\hline$\beta_{y}^{180}$ & 0,3005 & 2,72 & 0,3238 & 3,24 & 0,3035 & 2,30 \\
\hline$R^{2}$ & 0,84 & & 0,83 & & 0,85 & \\
\hline$\beta_{0}{ }^{360}$ & 0,0517 & 3,12 & 0,0527 & 3,63 & 0,0561 & 2,90 \\
\hline$\rho^{360}$ & 0,7939 & 8,51 & 0,7789 & 16,23 & 0,8470 & 9,21 \\
\hline$\beta_{\pi}^{360}$ & $-0,1398$ & $-2,10$ & $-0,1343$ & $-2,40$ & $-0,1818$ & $-2,37$ \\
\hline$\beta_{s}^{360}$ & 1,0582 & 2,51 & 1,092 & 3,06 & 1,1003 & 2,60 \\
\hline$\beta_{y}^{360}$ & 0,3180 & 1,89 & 0,3268 & 2,17 & 0,1836 & 0,84 \\
\hline$R^{2}$ & 0,83 & & 0,84 & & 0,84 & \\
\hline
\end{tabular}

Fuente: elaboración propia.

Nota: Número total: 216 observaciones del sistema. En el caso del método generalizado de momentos, la estadística J no rechazó la hipótesis nula de validez de los instrumentos probados. Los instrumentos utilizados fueron los desfases 1 y 2 de las variables explicativas.

$R^{2}$ : Bondad de ajuste. 
de acuerdo con el vencimiento. En general, los resultados señalan que cuanto mayor sea el vencimiento mayor es la repercusión de la política fiscal. Esto se observa claramente en el gráfico 5, en que se presenta el parámetro que mide el efecto del superávit primario en el período comprendido entre el tercer trimestre de 1999 y el cuarto trimestre de 2008 en conformidad con el vencimiento.

Para evaluar la solidez de los resultados obtenidos, el modelo se aplicó nuevamente a una submuestra que cubre el período que va del primer trimestre de 2003 al cuarto trimestre de 2008, excluido el lapso más volátil por cuenta de los innumerables choques de oferta que se concentraron en el período 1999-2002 (véase el cuadro 5). De acuerdo con el gráfico 2, el tiempo excluido corresponde al período en que las diversas primas de riesgo son más volátiles.

Los nuevos resultados denotan que solo en las primas más largas (en particular, en la de 360 días) se observa un efecto del superávit primario en la tasa de interés. En relación con los demás parámetros, se puede constatar que los resultados son equivalentes a los obtenidos anteriormente con un efecto negativo de la inflación y positivo de la brecha del producto.

Como conclusión se puede inferir que, además de incrementar la prima de riesgo, las reducciones en el superávit primario pueden aumentar la inclinación de la estructura temporal. Esa conclusión es muy parecida a los resultados obtenidos por Evans (1985, 1987a y 1987b) al estudiar los efectos de los déficits fiscales en la tasa de interés norteamericana.

En el cuadro 6 se presenta la repercusión de la prima de riesgo en el tipo de cambio, efecto que parece ser decreciente de acuerdo con el vencimiento y más pequeño en los tres casos presentados (360 días, 180 días o 120 días). El efecto del superávit primario en el tipo de cambio tiene lugar, por consiguiente, en la presión ejercida sobre la prima de riesgo. Sin embargo, al contrario de los resultados obtenidos en la estructura temporal, donde el superávit primario posee efectos mayores conforme con el vencimiento, en el caso del tipo de cambio sus repercusiones son compensadas en la medida en que las primas de riesgo con vencimientos más largos tiene menor influencia en la dinámica del tipo de cambio.

En el gráfico 6 se presenta la evolución del tipo de cambio y la previsión del modelo con la prima de riesgo de 360 días. Es importante observar que, si bien el modelo parece no tener un buen ajuste al inicio de la muestra, su poder de predicción mejora considerablemente a lo largo del tiempo. Gran parte de esa mejora obedece al modelado del valor de equilibrio como variable en el tiempo, aunque la significación estadística de la prima de riesgo no se deba necesariamente a ese modelado. Este hecho puede verificarse en la última columna del cuadro 6, en que se indica el desempeño del modelo con intercepto invariable en el tiempo. Por último, cabe señalar que el efecto en el tipo de cambio es cuantitativamente pequeño, aunque significativo desde el punto de vista estadístico.

En términos generales, los resultados indican un marcado efecto expansionista de la política fiscal, sin grandes repercusiones colaterales en el equilibrio macroeconómico en términos de desequilibrio externo e incremento de la tasa de interés. En términos económicos, esa estrategia de corto plazo tiene sentido debido al gran mercado interno brasileño, que absorbe casi por completo el efecto de las políticas adoptadas. En países más dependientes del comercio internacional, es posible que la mayor parte del impulso fiscal estimule las importaciones y tenga una eficacia menor que la estimada en el caso del Brasil.

\section{Efecto del superávit primario según el vencimiento}
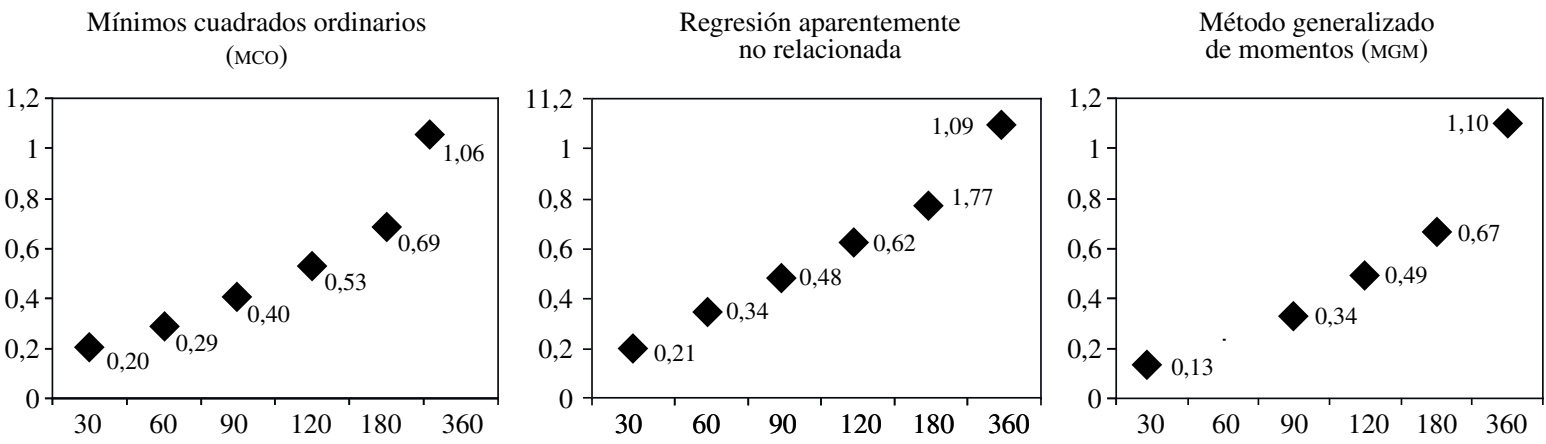

Fuente: elaboración propia. 
CUADRO 5

Determinantes macroeconómicos de la prima de riesgo, primer trimestre de 2003 al cuarto trimestre de 2008

\begin{tabular}{|c|c|c|c|c|c|c|}
\hline \multirow{2}{*}{ Variables } & \multicolumn{2}{|c|}{$\begin{array}{l}\text { Mínimos cuadrados } \\
\text { ordinarios }\end{array}$} & \multicolumn{2}{|c|}{$\begin{array}{l}\text { Regresión aparentemente no } \\
\text { relacionada }\end{array}$} & \multicolumn{2}{|c|}{$\begin{array}{l}\text { Método generalizado de } \\
\text { momentos }\end{array}$} \\
\hline & Coeficiente & Estadística t & Coeficiente & Estadística t & Coeficiente & Estadística t \\
\hline$\beta_{0}{ }^{30}$ & 0,0028 & 0,58 & 0,0029 & 0,74 & 0,0024 & 0,68 \\
\hline$\rho^{30}$ & 0,6326 & 7,50 & 0,6355 & 13,02 & 0,6257 & 11,29 \\
\hline$\beta_{\pi}^{30}$ & $-0,0339$ & $-3,08$ & $-0,0340$ & $-4,64$ & $-0,0326$ & $-4,16$ \\
\hline$\beta_{s}^{30}$ & 0,0314 & 0,28 & 0,0333 & 0,36 & 0,0231 & 0,28 \\
\hline$\beta_{y}^{30}$ & 0,0680 & 2,76 & 0,0680 & 3,10 & 0,0739 & 4,20 \\
\hline$R^{2}$ & 0,83 & & 0,83 & & 0,83 & \\
\hline$\beta_{0}{ }^{60}$ & 0,0049 & 0,70 & 0,0045 & 0,80 & 0,0041 & 0,86 \\
\hline$\rho^{60}$ & 0,6277 & 7,24 & 0,6188 & 12,92 & 0,6187 & 10,11 \\
\hline$\beta_{\pi}^{60}$ & $-0,0421$ & $-3,21$ & $-0,0414$ & $-3,92$ & $-0,0400$ & $-3,47$ \\
\hline$\beta_{s}^{60}$ & 0,0737 & 0,45 & 0,0655 & 0,49 & 0,0588 & 0,53 \\
\hline$\beta_{y}^{60}$ & 0,1159 & 3,28 & 0,1162 & 3,71 & 0,1258 & 5,02 \\
\hline$R^{2}$ & 0,83 & & 0,83 & & 0,83 & \\
\hline$\beta_{0}^{90}$ & 0,0081 & 0,93 & 0,0074 & 1,06 & 0,0073 & 1,25 \\
\hline$\rho^{90}$ & 0,6187 & 7,05 & 0,6044 & 12,61 & 0,6089 & 9,16 \\
\hline$\beta_{\pi}^{90}$ & $-0,0488$ & $-2,94$ & $-0,0473$ & $-3,56$ & $-0,0461$ & $-3,30$ \\
\hline$\beta_{s}^{90}$ & 0,1467 & 0,73 & 0,1309 & 0,79 & 0,1292 & 0,99 \\
\hline$\beta_{y}^{90}$ & 0,1588 & 3,56 & 0,1598 & 4,05 & 0,1718 & 5,51 \\
\hline$R^{2}$ & 0,83 & & 0,83 & & 0,83 & \\
\hline$\beta_{0}^{120}$ & 0,0133 & 1,29 & 0,0121 & 1,44 & 0,0122 & 1,69 \\
\hline$\rho^{120}$ & 0,6083 & 6,96 & 0,5879 & 12,24 & 0,5971 & 8,15 \\
\hline$\beta_{\pi}^{120}$ & $-0,0558$ & $-2,76$ & $-0,0532$ & $-3,29$ & $-0,0524$ & $-2,98$ \\
\hline$\beta_{s}^{120}$ & 0,2652 & 1,09 & 0,2398 & 1,19 & 0,2431 & 1,53 \\
\hline$\beta_{y}{ }^{120}$ & 0,2073 & 3,78 & 0,2100 & 4,36 & 0,2243 & 5,49 \\
\hline$R^{2}$ & 0,84 & & 0,84 & & 0,83 & \\
\hline$\beta_{0}{ }^{180}$ & 0,0186 & 1,51 & 0,0171 & 1,69 & 0,0173 & 1,96 \\
\hline$\rho^{180}$ & 0,5945 & 6,80 & 0,5717 & 11,77 & 0,5824 & 7,53 \\
\hline$\beta_{\pi}^{180}$ & $-0,0636$ & $-2,60$ & $-0,0601$ & $-3,06$ & $-0,0593$ & $-2,71$ \\
\hline$\beta_{s}^{180}$ & 0,3867 & 1,34 & 0,3553 & 1,47 & 0,3673 & 1,90 \\
\hline$\beta_{y}^{180}$ & 0,2611 & 3,89 & 0,2655 & 4,53 & 0,2827 & 0,00 \\
\hline$R^{2}$ & 0,84 & & 0,83 & & 0,83 & \\
\hline$\beta_{0}^{360}$ & 0,0330 & 2,23 & 0,0329 & 2,57 & 0,0309 & 2,69 \\
\hline$\rho^{360}$ & 0,5552 & 6,93 & 0,5529 & 11,49 & 0,5380 & 8,14 \\
\hline$\beta_{\pi}^{360}$ & $-0,0695$ & $-2,06$ & $-0,0689$ & $-2,58$ & $-0,060$ & $-1,94$ \\
\hline$\beta_{s}^{360}$ & 0,7363 & 2,10 & 0,7338 & 2,39 & 0,6991 & 2,88 \\
\hline$\beta_{y}{ }^{360}$ & 0,3729 & 4,11 & 0,3739 & 4,80 & 0,4132 & 4,61 \\
\hline$R^{2}$ & 0,84 & & 0,84 & & 0,84 & \\
\hline
\end{tabular}

Fuente: elaboración propia.

Nota: Muestra total: 144 observaciones. En el caso del método generalizado de momentos, la estadística J no rechazó la hipótesis nula de validez de los instrumentos probados. Los instrumentos utilizados fueron los desfases 1 y 2 de las variables explicativas.

$R^{2}$ : Bondad de ajuste. 
CUADRO 6

Efecto de la prima de riesgo en el tipo de cambio

\begin{tabular}{lcccc}
\hline Modelo & $\begin{array}{c}\text { Coeficiente } \\
\text { (Estadística t) }\end{array}$ & $\begin{array}{c}\text { Coeficiente } \\
\text { (Estadística t) }\end{array}$ & $\begin{array}{c}\text { Coeficiente } \\
\text { (Estadística t) }\end{array}$ & $\begin{array}{c}\text { Modelo } \\
\text { "invariable" }\end{array}$ \\
\hline$\psi_{t}$ & $4,69(743,9)$ & $4,69(766,7)$ & $4,69(751,2)$ & $4,68(81,74)$ \\
$r_{t}^{360}$ & $0,0172(4,07)$ & - & - & $0,0248(1,99)$ \\
$r_{t}^{180}$ & - & $0,0253(4,00)$ & - & - \\
$r_{t}^{120}$ & - & - & $0,0305(3,85)$ & - \\
$R^{2}$ & 0,8451 & 0,8435 & 0,8399 & 0,1177 \\
\hline
\end{tabular}

Fuente: elaboración propia.

$R^{2}$ : Bondad de ajuste.

GRÁFICO 6

Comparación del poder de predicción del modelo de 360 días

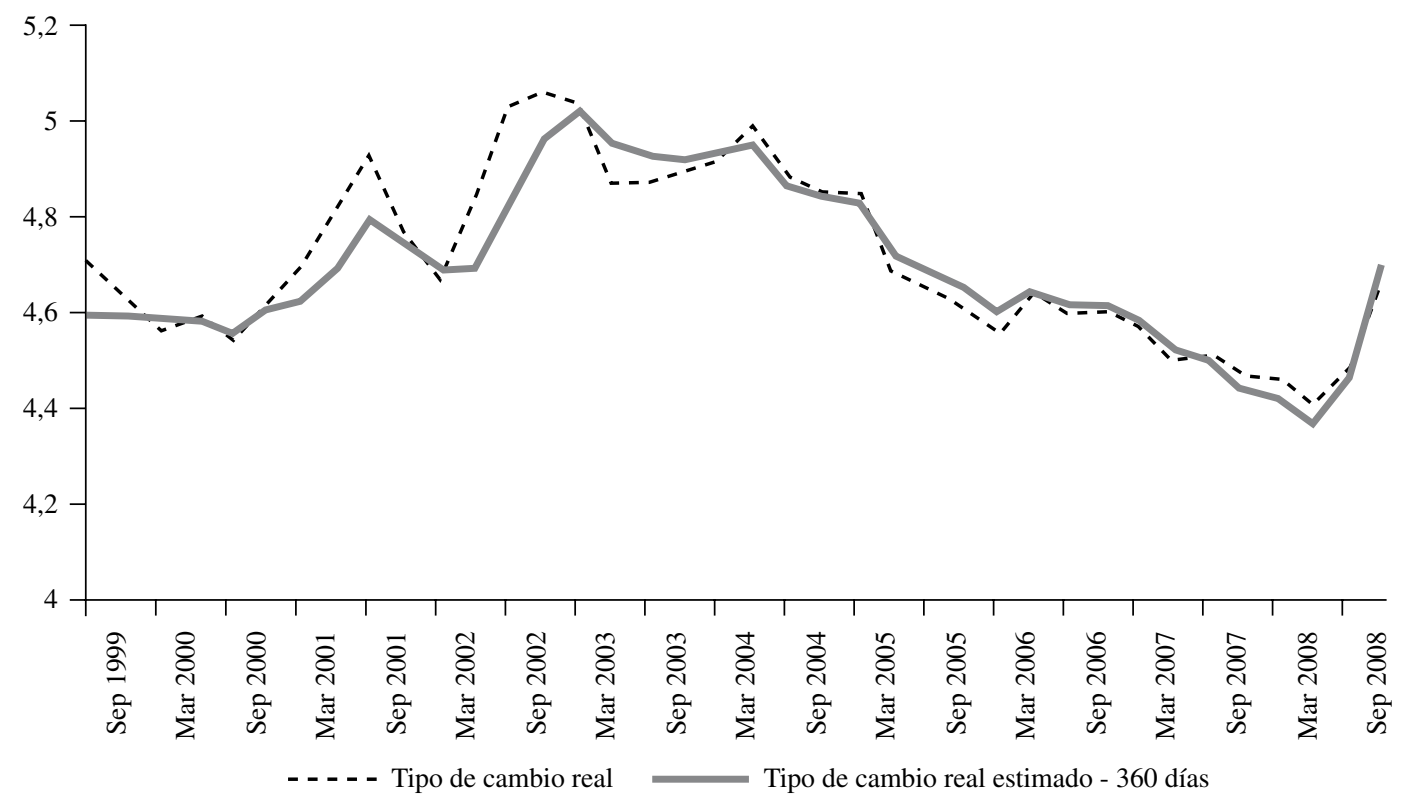

Fuente: elaboración propia. 


\section{$\mathrm{V}$}

\section{Conclusiones}

La rapidez con que la crisis financiera internacional se instauró en la economía brasileña en el último trimestre de 2008 tuvo efectos avasalladores en la economía real y exigió respuestas igualmente rápidas de política económica, con grandes repercusiones macroeconómicas.

El objetivo de este artículo fue presentar el efecto macroeconómico de corto plazo de la reducción de la meta de superávit primario. La reducción del superávit primario fue una respuesta de política económica que, además de mantener los gastos presupuestarios con miras a sustentar la demanda agregada, apuntó a acelerar el nivel de inversiones públicas. De este modo, en el artículo se evaluó el efecto de la reducción del superávit primario en el nivel de actividad, la estructura temporal de la tasa de interés y el tipo de cambio.

En los resultados se pudo apreciar que la reducción del superávit primario debe aumentar el nivel de actividad en magnitudes significativas. A su vez, se advirtió que al utilizar un modelo de tres ecuaciones, de uso común en los bancos centrales, la reducción del superávit primario debe incrementar el nivel de actividad económica convirtiéndose, por ende, en una política eficaz de recuperación de dicha actividad.

También se observó que la reducción del superávit primario puede tener como contrapartida el aumento de la inclinación de la estructura temporal de la tasa de interés, sobre todo en el intervalo más largo, y la desvalorización del tipo de cambio. Sin embargo, el efecto en el tipo de cambio puede considerarse pequeño, de modo que sería exagerado argumentar que la política fiscal anticíclica podría ser responsable de la profundización del desequilibrio externo.

En general, los resultados dejan ver que la política fiscal anticíclica debe producir efectos satisfactorios en el nivel de actividad, sin producir repercusiones colaterales negativas. En suma, si bien el nivel de actividad tendrá que estimularse considerablemente, es importante destacar que el efecto en la estructura temporal deberá ocurrir solo mediante las tasas más largas y la influencia en el equilibrio externo - al ejercer presión sobre el tipo de cambio- deberá ser pequeña.

APÉNDICE

Prueba de Ng y Perron (2001) de raíz unitaria

\begin{tabular}{llcc}
\hline Variable & \multicolumn{1}{c}{ Modelo } & Nivel de significación (5\%) & Estadística de prueba (MZa) \\
\hline$y$ & constante & $-8,10$ & $-26,74$ \\
$\pi$ & constante & $-8,10$ & $-12,99$ \\
$i$ & constante & $-8,10$ & $-17,71$ \\
$s$ & constante y tendencia & $-17,30$ & $-10,46$ \\
$q$ & constante y tendencia & $-17,30$ & $-10,71$ \\
$\mathrm{~d}(q)$ & constante & $-8,10$ & $-36,95$ \\
\hline
\end{tabular}

Fuente: elaboración propia.

Prueba de Saikkonen y Lutkepohl (2002) de raíz unitaria

\begin{tabular}{clccr}
\hline Variable & \multicolumn{1}{c}{ Modelo } & Fecha de la ruptura & Nivel de significación (5\%) & Estadística de prueba \\
\hline$y$ & constante & 2004 (2do. trimestre) & $-2,88$ & $-3,77$ \\
$\pi$ & constante & 2003 (3er. trimestre) & $-2,88$ & $-2,91$ \\
$i$ & constante & 2002 (3er. trimestre) & $-2,88$ & $-2,97$ \\
$s$ & constante y tendencia & 2003 (1er. trimestre) & $-3,03$ & $-3,13$ \\
$q$ & constante y tendencia & 2003 (1er. trimestre) & $-3,03$ & $-2,08$ \\
\hline
\end{tabular}

Fuente: elaboración propia. 
Andrade, J.P. y M.C.C. Pires (2009), "Uma análise da transmissão da política monetária e o canal da dívida pública com aplicação aos dados brasileiros", Texto para discussão, № 1379, Río de Janeiro, Instituto de Política Económica Aplicada (IPEA).

Bacha, E. (2008), "O choque externo e a resposta possível”, Como reagir à crise? Políticas econômicas para o Brasil, E. Bacha e I. Goldfajn (orgs.), Río de Janeiro, Editora Imago.

Balassa, B. (1964), "The purchasing-power parity doctrine: a reappraisal", Journal of Political Economy, vol. 72, Chicago, University of Chicago Press.

Bardsen, G. y otros (2005), The Econometrics of Macroeconomic Modelling, Nueva York, Oxford University Press.

Barro, R. (1979), "On the determination of the public debt", Journal of Political Economy, vol. 87, $\mathrm{N}^{\mathrm{o}}$ 5, Chicago, University of Chicago Press.

Blanchard, O. y F. Giavazzi (2004), "Improving the SGP through a proper accounting of public investment", CEPR Discussion Papers, No 4220, Londres, Centre for Economic Policy Research.

Blinder, A. (2006), "The case against discretionary fiscal policy", The Macroeconomics of Fiscal Policy, R. Kopcke, G. Tootell y R. Triest, Cambridge, Massachusetts, The MIT Press.

Bohn, H. (1997), "The behavior of U.S. public debt and deficits", The Quarterly Journal of Economics, vol. 113, № 3, Cambridge, Massachusetts, The MIT Press.

Clements, M. y D. Hendry (2008), Forecasting Economic Time Series, Cambridge, Cambridge University Press.

Commandeur, J.J.F. y S.J. Koopman (2007), An Introduction to Space State Time Series Analysis, Nueva York, Oxford University Press.

Dornbusch, R. (1976), "Expectations and exchange rate dynamics", Journal of Political Economy, vol. 84, № 6, Chicago, Chicago University Press.

Evans, P. (1987a), "Interest rates and expected future budget deficits in the United States", Journal of Political Economy, vol. 95, $\mathrm{N}^{\mathrm{o}}$ 1, Chicago, Chicago University Press.

(1987b), "Do budget deficits raise nominal interest rates? Evidence from six countries", Journal of Monetary Economics, vol. 20, $\mathrm{N}^{\circ} 2$, Amsterdam, Elsevier.

(1985), "Do large deficits produce high interest rates", American Economic Review, vol. 75, № 1, Nashville, Tennessee, American Economic Association.

Guillén, O.T. y B. Tabak (2007), "Characterizing the Brazilian term structure of interest rates", Anais do XXXV Encontro Nacional de Economia, N ${ }^{\circ}$ 108, Salvador, Asociación Nacional de Centros de Posgrado en Economía (ANPEC).

Haavelmo, T. (1944), "The probability approach in econometrics", Econometrica, vol. 12, Bethesda, Econometric Society.
Hemming, R. y T. Ter-Minassian (2004), "Making room for public investment", Finance and Development, Washington, D.C., Fondo Monetario Internacional, diciembre.

Hoover, K.D., S. Johansen y K. Juselius (2008), “Allowing the data to speak freely: the macroeconomics of the cointegrated vector autoregression", American Economic Review, vol. 98, № 2 , Nashville, Tennessee, American Economic Association.

Juselius, K. (2007), "The PPP puzzle: what the data tell when allowed to speak", The Handbook of Econometrics, T. Mills y K. Patterson (comps.), Londres, Palgrave.

Lambertini, L. y R. Rovelli (2003), "Monetary and fiscal policy coordination and macroeconomics stabilization: a theoretical analysis", Working Papers, $\mathrm{N}^{\mathrm{0}}$ 464, Bolonia, Universidad de Bolonia.

Lima, A. y J. Issler (2003), "A hipótese das expectativas na estrutura a termo da taxa de juros no Brasil: uma aplicação de modelos de valor presente", Revista brasileira de economia, vol. 57, $N^{o}$ 4, Río de Janeiro, Fundación Getulio Vargas.

Ng, S. y P. Perron (2001), "Lag length selection and the construction of unit root tests with good size and power", Econometrica, vol. 69, N 6, Bethesda, Econometric Society.

Parnes, B. e I. Goldfajn (2008), "Como reagir à crise: política fiscal”, Como reagir à crise? Políticas econômicas para o Brasil, E. Bacha e I. Goldfajn (orgs.), Río de Janeiro, Editora Imago.

Rogoff, K. (1996), "The purchasing power parity puzzle", Journal of Economic Literature, vol. 34, No 2, Nashville, Tennessee, American Economic Association.

Rothenberg, T. y J. Stock (1997), "Inference in a nearly integrated autoregressive model with nonnormal innovations", Journal of Econometrics, vol. 80, № 2, Amsterdam, Elsevier.

Saikkonen, P. y H. Lutkepohl (2002), "Testing for a unit root in a time series with a level shift at unknown time", Econometric Theory, vol. 18, Cambridge, Cambridge University Press.

Samuelson, P. (1964), "Theoretical notes on trade problems", Review of Economics and Statistics, vol. 46, Cambridge, Massachusetts, The MIT Press.

Silva, A.M.A. y M.C.C. Pires (2008), "Dívida pública, poupança em conta corrente do governo e superávit primário: uma análise de sustentabilidade", Revista de economia política, vol. $28, \mathrm{~N}^{\circ} 4$, São Paulo, Centro de Economía Política.

Tabak, B. y S. Andrade (2003), "Testing the expectations hypothesis in the Brazilian term structure of interest rates", Revista brasileira de finanças, vol. 1, № 2, São Paulo, Sociedade Brasileira de Finanças.

Tobin, J. (1982), Asset Accumulation and Economic Activity: Reflections on Contemporary Macroeconomic Theory, Chicago, The University of Chicago Press. 